\title{
Same but different: meaning-making among refugee and non-refugee youths
}

Ragnhild Dybdahl, Torgeir Sørensen, Hans A. Hauge, Kjersti Røsvik, Lars Lien and Ketil Eide

\begin{abstract}
Purpose - There is substantial research on the experiences, needs and well-being of unaccompanied refugee adolescents, but less is known about existential aspects of their lives. The purpose of the current study is to explore existential meaning-making among unaccompanied refugee children.

Design/methodology/approach - The informants in this study are young unaccompanied refugees $(n=30)$ living in Norway, and young Norwegians $(n=46)$. The authors undertook a secondary analysis of in-depth qualitative refugee interview data and a quantitative analysis of questionnaire data from Norwegian informants.

Findings - Both the refugee youths and the Norwegian youths expressed that social relationships and connections to others were most important for meaning. Moreover, both groups emphasized the importance of relatedness and generativity, i. e. commitment to worldly affairs beyond one's immediate needs. The main differences between the two groups were related to the significance attached to religion and to loneliness.
\end{abstract}

Research limitations/implications - The comparison between the two groups is only possible to some degree. Secondary analyses have some limitations, as well as strengths.

Practical implications - The findings may be useful for supporting young refugees, as they provide insights into less-studied aspects of their lives.

Originality/value - The originality of this study lies in the focus on and broad interpretation of meaning, of secondary data analyses, and of comparisons between youths that are refugees versus non-refugees.

Keywords Unaccompanied minor refugees, Existential meaning, Meaning-making, Norway, Secondary analyses

Paper type Research paper

\section{Introduction}

Every year, thousands of children and youths travel alone to seek refuge and asylum in Europe, and many resettle in a host country. Unaccompanied minor asylum seekers and refugees are often resourceful and resilient. Numerous studies have documented how people may adapt and thrive even after severe adversity (Bonanno and Mancini, 2008). However, the lives of these children are often made difficult due to current life stressors, as well as past exposure to dangers and loss.

To understand young refugees' adaption and development, existential aspects of their lives must also be included. This is illustrated by the significance attributed to multimodal interventions and the interplay between many variables in models for the study of refugee children and youth, including social bonds, a sense of justice; identity; and existential meaning (Fazel, 2018; Silove, 2013). The purpose of the current study is to explore meaningmaking among unaccompanied refugee children and asylum-seeking adolescents.

Key themes for adolescents in general include considerations related to future goals, values, independence and development of personal identity (Beal et al., 2016; Crosnoe and Johnson, 2011). Thus, issues related to meaning are important not only to refugees
(Information about the authors can be found at the end of this article.)

Received 23 February 2021 Revised 4 June 2021 Accepted 5 July 2021

(C) Ragnhild Dybdahl, Torgeir Sørensen, Hans A. Hauge, Kjersti Røsvik, Lars Lien and Ketil Eide. Published by Emerald Publishing Limited. This article is published under the Creative Commons Attribution (CC BY 4.0) licence. Anyone may reproduce, distribute, translate and create derivative works of this article (for both commercial and noncommercial purposes), subject to full attribution to the original publication and authors. The full terms of this licence may be seen at http://creativecommons. org/licences/by/4.0/legalcode

The authors would like to thank all participants in the studies. We also thank Wøien

Foundation for financial support to the original qualitative study and Innlandet Hospital Trust (Grant No. 150267) for financial support to the original quantitative study. 
but also to young people in general. To make salient characteristics of meaning-making among the participants, we therefore explored some similarities and differences in "sources of meaning" drawn from interviews among the young refugees, along with findings from Norwegian youth of approximately the same age. The design of the study does not allow us to determine which aspects of the youths' meaning-making are due to refugee experiences, but comparing meaning among young Norwegians and young refugees in Norway, allows exploration of some such aspects. Comparison of the two groups related to others factors, shows that cultural, social and economic contexts, as well as maturity, are important. What sources of meaning do the refugee youths mention, and in what way are they equal and different to Norwegian youths' sources of meaning?

\section{Previous research and conceptual framework}

Substantial research has been done on the experiences, identity, needs and well-being of unaccompanied refugee children and asylum-seeking adolescents (Ehntholt et al., 2018; Jensen et al., 2015; Wernesjö, 2015; Jensen et al., 2019; Hebebrand et al., 2016; Vervliet et al., 2014; Fazel et al., 2012; Sierau et al., 2019; Oppedal et al., 2020; Hayes and Endale, 2018), often focusing on post-traumatic stress (Fazel, 2018). Some attention, although limited, has been paid to the construct of meaning among refugees, primarily among adults, and often related to trauma, coping, growth and spirituality (Matos et al., 2018; Tekie, 2018). Existential aspects may be considered part of health and well-being, in particular eudaimonic well-being. This type of well-being has been proposed to comprise phenomena such as psychological and social well-being, including positive relations, personal growth, self-realization, purpose in life, social coherence and autonomy, as well as meaning and strengths, and behaviors and orientations such expressing gratitude, persevering and meaning-making (Røysamb and Nes, 2016). Less is known about existential aspects of the lives of young refugees.

Meaning in life can be conceptualized in many ways, but is often referred to a sense of coherence and purpose in one's life beyond the present and individual, and encompasses several dimensions, such as beliefs, values and goals (Delle Fave and Soosai-Nathan, 2014; Steger, 2012). Importantly, meaning can foster health, resilience and adaptability in handling challenges and integrate a sense of identity. Meaning is increasingly understood as a core component of well-being and of how humans develop and adapt to demands they encounter (Delle Fave and Soosai-Nathan, 2014). For adolescents and young adults, meaning-making are important parts of identity development.

Conceptual models and empirical findings highlight the role of relationships and connectedness in the construction of meaning throughout life. Frankl's claim that humans are characterized by a "will to meaning" (Frankl, 1985), would indicate that all people have a drive to find meaning in life. This may be particularly salient in times of hardship and suffering, and when separated from loved ones and familiar environments. Based on developmental psychology, one would also expect adolescents and young people to be preoccupied with making sense of life and working out their own significance and ambitions. Thus, it would be reasonable to expect existential topics related to social connections and relationships to be important to young refugees who are separated from their families (Delle Fave and Soosai-Nathan, 2014).

Schnell (Schnell, 2011; Schnell, 2009) has identified 26 different sources of meaning. These sources have been grouped within six different dimensions (Table 1) (Sørensen et al., 2019). Well-being and relatedness contain commitment, enjoyment, sensitivity and warmth in privacy and company. As such, this dimension embraces both caring for oneself and caring for others. Order and tradition are about obligation to principles, common sense and the tried and tested. As search for objects beyond immediate needs, self-transcendence has two components. In vertical self-transcendence people search for an immaterial, supernatural reality in the frame of organized religiosity and individual spirituality. 
Table 1 Dimensions and sources of meaning (Sørensen et al., 2019)

Well-being and

relatedness Order and tradition Vertical self-transcendance

Horizontal self-transcendance

Liberality

Accomplishment

Community

Practicality

Spirituality

Union with nature

Social commitment

Health

Reason

Religiosity

Harmony

Freedom

Achievement

Love

Morality

Self-knowledge

Individualism

Comfort

Development

Care

Challenge

Knowledge

Generativity

Horizontal self-transcendence is a search directed to worldly affairs beyond one's immediate needs like health, nature and social commitment. Liberality is an inwardly individually oriented dimension where freedom is a prominent factor. Finally, the dimension accomplishment emphasizes the achievement of various things by utilizing inherent resources and capabilities, including generativity encompassing an unselfish contribution to others' good living conditions across generations.

\section{Method}

The informants in this study are young unaccompanied refugees $(n=30)$ living in Norway and young Norwegians $(n=46)$. The data from the refugee informants are qualitative and based on personal interviews, while the data from the Norwegian informants are quantitative, based on standardized questionnaires.

\section{Participants in the qualitative study}

The refugee informants were from 15 to 19 years of age. They were from different countries, but the majority came from Afghanistan, and nearly all were male. The informants had recently been granted permanent residence. Many had experienced hardships in terms of socioeconomic conditions, political violence, being displaced or having refugee status in several countries and having had a dangerous journey. The conditions in Afghanistan have been described as dispiriting, causing many young people to become cynical and explaining why so many are seeking asylum abroad (Alemi et al., 2018). A study by PanterBrick and colleagues showed that despite the disillusionment, many young Afghans demonstrated hope and resilience (Panter-Brick et al., 2008).

Resettling in Norway also involved many challenges. The duration of this process varied, but during the asylum-seeking process, minors under 15 years of age are housed in care centers operated by child welfare services, while minors between 15 and 18 years of age are housed in reception centers run by immigration authorities (Eide et al., 2020). They receive practical help, social services, care and education until they are between 20 and 23 years of age. Often 3-4 minors share a home attended by social workers day and night, and few live in foster homes or by themselves. The challenges of resettlement are many, including adapting to a new language and culture, and the changing relationships with helpers, peers and transnational relations with their families (Eide et al., 2020).

\section{Secondary qualitative analysis}

The refugee participants were part of a qualitative study called «Care, expectations and effort. Resettlement of unaccompanied refugee minors in Norway» about their life situation, well-being and integration (Eide et al., 2020).

We undertook secondary analysis (Hinds et al., 1997; Stewart et al., 1993) of in-depth qualitative interview data. We considered that data from the original study were suitable for the secondary analysis as the purpose of the original study is relevant also to the theme of 
the current analysis. Furthermore, the data were deemed sufficient and of satisfactory quality to address the topics of the current study, and time interval since the original study had not made the current findings less relevant. These criteria are central to assessing the use of secondary qualitative data (Stewart et al., 1993; Hinds et al., 1997).

In the original study (Eide et al., 2020), the interviewers opted for ethnographic interviewing, encouraging the youths to take a narrative or storytelling approach rather than merely responding to questions (Herz and Lalander, 2017; Moshuus and Eide, 2016). Over time, the youths increasingly chose the interview issues and engaged in dialog about their understandings. Our methodological approach was influenced by our understanding of interviews as a means by which to construct, rather than extract, meanings (Braun and Clarke, 2006).

The themes identified in the original study were trust and distrust (of social workers and peers) and loss (of family, loneliness), consistent with narratives of vulnerability. However, there were also themes related to resourcefulness, such as reassessing and making changes in relationships with significant others.

The researchers of the original study pointed out that the complexity of their data allowed for research into multiple issues, and that their focus on one line of inquiry could have resulted in overlooking alternative understandings that were relevant for understanding resettlement processes (Eide et al., 2020). Thus, the secondary data were analyzed by five of the authors who jointly identified two themes for further study: "constructions of their families" and "existential questions in their lives". Next, the authors invited a new researcher, and they jointly analyzed the existential aspects of the data. By conducting a secondary analysis, we wanted to explore if and in what ways this topic could be understood in the interview data. Thus, the interviews were not conducted for the purpose of understanding meaning or existential issues but were still in line with the study's aim to better understand the lives of these young people.

\section{Quantitative investigation}

The initial findings on existential issues in the qualitative data were deemed interesting in view of an independent quantitative study (Sørensen et al., 2019), which led to the comparison with data using a different population and methodology. Thus, in an effort to better understand the young refugees, we compared the findings with data from Norwegian adolescents. The latter was a sample of 46 young adults 17-22 years old who were the youngest participants in a randomly collected sample of the Norwegian population drawn from the Norwegian National Registry ( $N=925$; for details, see Sørensen et al., 2019).

For measurement of affiliation to meaningfulness and the sources of meaning, the Sources of Meaning and Meaning in Life Questionnaire (SoMe) was used (Sørensen et al., 2019). In addition to meaningfulness ( 5 items), SoMe measures 26 different sources of meaning sorted into six different dimensions (Table 1) through 141 items. Each item is rated on a sixpoint Likert scale from 0 (totally disagree) to 5 (totally agree). Internal consistencies ranged from 0.70 to 0.82 for the six dimensions of the sources of meaning, 0.61 to 0.92 for the subscales and 0.71 for meaningfulness. For the quantitative analyses, mean sum scores and correlations were employed.

\section{Qualitative analysis}

We followed the consolidated criteria for reporting qualitative research (COREQ) guidelines, adapted to secondary analysis (Tong et al., 2007).

Thematic analysis was selected to identify patterns and broad themes in the data. Interview transcripts were analyzed thematically using a combination of inductive and deductive coding (Ritchie et al., 2013). Applying thematic analysis (Braun and Clarke, 2006), we 
started by open coding to familiarize ourselves with the interview transcripts. We tried to identify patterns and themes by thematic analysis of the data. The thematic analysis followed six phases in line with Braun and Clarke (2006). These were: 1 Familiarizing ourselves with the data, 2 Generating initial codes, 3 Searching for themes, 4 Reviewing themes, 5 Defining and naming themes, 6 Creating a narrative using extracts, or meaningful units, from the interviews with passages that illustrate the analytic narrative. As a way to mitigate the problem of comparing results using different populations and methodologies, these themes were also analyzed in terms of dimensions of sources of meaning described as described above (Sørensen et al., 2019) (see Table 2 for examples).

After the researchers independently had familiarized themselves with the data, a coding frame was developed as a result of a process of discussions and comparisons of each researcher's selected quotes and themes.

During the analysis, discrepancies were resolved by discussion, and minor amendments were made to the coding frame. During the analysis we recorded the newly identified codes and decided that further codes and themes were possible, but that they lay outside the purpose of the current study. We considered that we had sufficient information power (Malterud et al., 2016) when no additional codes related to the selected topic were identified. More meaning units were available in the data but were similar or overlapped with those that had already been selected. The final stage of analysis investigated the themes to identify a typology of existential topics, which were in turn applied to the raw data to check for fit.

\section{Ethics}

Fully informed consent was obtained for the quantitative investigation. The study was also registered with the Norwegian Centre for Research Data (Project No. 42438) (Sørensen et al., 2019). For the qualitative study, the secondary analysis was in line with the aims of the primary research study and original ethical approvals. The original research project was reported to the Norwegian Centre for Research Data (Project No. 31551). Informed consent was obtained, and the participants were informed of their right to withdraw from the study at any time. Unaccompanied refugee minors are a particularly vulnerable group of children and adolescents (Hopkins, 2008; Fladstad, 2014). Therefore, the original research team reflected on ethical issues related to the research process continually during the project period. In the secondary analysis, efforts were made to interpret the informants' statements within the frame of the original study. The principal investigator of the original study reviewed the findings of the secondary analysis to ensure that interpretations were still in line with the original context and that participants' statements were reported reliably.

Table 2 Example of summary of coding of qualitative interviews $(n=30)$

\begin{tabular}{|c|c|c|c|}
\hline Meaning unit & Code & Theme & Dimension in meaning making \\
\hline $\begin{array}{l}\text { "I have always prayed to God for the good that we } \\
\text { shall have" }\end{array}$ & God & Explicit Religion & $\begin{array}{l}\text { Vertical self-transcendence } \\
\text { (search for objects beyond immediate } \\
\text { needs) }\end{array}$ \\
\hline $\begin{array}{l}\text { "The only thing that gives me hope, the only thing } \\
\text { that gives me meaning in life to continue, is my } \\
\text { mother. If not because of my mother, then I will not } \\
\text { think about myself..." } \\
\text { "I do not care if I get a diploma, if I go to university } \\
\text { or anything. I do not care about this. First, I think } \\
\text { that family is all for me. }\end{array}$ & $\begin{array}{l}\text { Mother } \\
\text { Family }\end{array}$ & $\begin{array}{l}\text { Hope, comfort, } \\
\text { interconnectedness } \\
\text { Social commitment }\end{array}$ & $\begin{array}{l}\text { Horizontal self-transcendence } \\
\text { Horizontal self-transcendence }\end{array}$ \\
\hline
\end{tabular}




\section{Results}

Three main themes emerged from the analysis of the qualitative interviews. These were related to God/religion, family/mother/social relations and being alone/lonely. There were also a number of other themes, such as duty to help others, well-being through accomplishment and lack of hope or meaning. However, these themes often seemed to be linked to the main themes, such as to family or loneliness (Table 2). Many statements (meaning units) contained themes that point to several of these codes and dimensions.

\section{Religion}

The participants reported religion to be a natural part of their lives and mentioned various contexts, for example in connection with showing gratefulness. Religious belief, prayer, God and angels were referred to as sources of comfort, help and meaning. These were often linked to other main themes, such as family and loneliness. One boy said, for example, "I believe in God, so I do not feel lonely". Another said: "I prayed to God to take care of my brother".

However, there are some statements that indicate that God and religion play crucial roles in providing meaning in themselves, and faith was referred to as the most important thing in life. Similarly, religion was referred to as a way to cope with hardship, such as in the following statement, when a boy had talked about God, and was asked what religion meant to him: "Religion means everything. The journey from Afghanistan was awful. I have managed because I prayed to God, and then he was leading me."

\section{Mother, family and social connectedness}

Family, and in particular the mother, emerged as a main source of meaning; for example, as a reason for living or for working. The participants spoke about family as a source of motivation to perform important activities such as homework, education, future work and current efforts to earn money.

The link between activity and family commitment is illustrated in this statement: "Soon I will have a job and can send money. I can send money now, even though I am broke. But I borrow money from my friends to send to them, just to show that I am fine". Although informants mentioned that they tried to send money because they knew their family needs it, it was often emphasized that the families did not expect anything from them. In speaking about his family, one boy expressed this theme:

Informant: They say: we do not need your money, you are you, you should enjoy yourself.

Interviewer: But why do you send money, then?

Informant: One must do that, you know, it is family.

The expressions of social commitment often seemed to be linked to care, love, morality and tradition. The mother is mentioned as the motivation for prevailing and succeeding. Sometimes this is explained by the informant as something he wants to do to support the mother and provide for the family. However, in addition, it seemed that supporting the family was motivated by a strong wish not to be a burden, not to cause worries for the mother and the family.

In one of the interviews there was an interaction that may further illustrate the importance attached to the mother. An informant said that he had been told by a woman that some mothers would send their children abroad so that the rest of the family could follow later. The informant protested and said this was not possible:

I told her that it is not like that. And a mother cannot expose us to danger in order to get here herself. She told me that some parents do that anyway, but I told her that nobody does that. All 
young people who are here have gone through many dangers and survived in order to get here and if they have come here, it is not in order to get the parents here. If the parents come, it is something else than what was planned.

The informant appeared shocked and refused to believe that mothers would not put their children's safety and welfare first. This statement corresponds to a theme which is salient in the interviews, namely the idea of what a mother is. This was illustrated in the following statement by another informant. He spoke about his mother and his family, and why he should keep his room clean and tidy:

The only thing that gives me hope, the only thing that gives me meaning in life to continue, is my mother. If not because of my mother, then I will not think about myself. Everything I do now is because of them [...] but if the day comes that my mother passes, if she is no more[...] Then I think everything will be very different. Then I will be lonely. Then there is no point anymore. Who shall you then show yourself to? Who shall you then live for? Shall I only clean for myself? And no matter what work you do, if mother does not exist, then it is only I and me alone.

This statement can be understood to mean that the mother and the family are main reason for working and carrying out everyday tasks; moreover, the theme of loneliness and being alone is linked to the ideas and feelings about the mother.

Alone and loneliness Being alone emerged as a theme in the material but related to several different topics. Being alone could mean to be lonely, as in this statement: "The worst is to be lonely. You are completely alone and must do everything yourself. If I only couldd not have to be alone for 15 minutes." The theme of being alone is salient, and sometimes seems to be an emotional topic, and as such related to well-being and lack of harmony.

Being alone is also linked to missing one's family and in particular the mother, as illustrated here: "I am very lonely. I miss my mamma all the time and call her all the time. I tell her everything is fine. God will help us if we pray. No one can give me happiness although I am searching everywhere. But I am religious and help poor people".

However, in some instances being alone also seems to be linked to being independent and self-reliant. One boy linked this to the future when saying "If I am going to be a dentist, I have to do it myself. No matter how difficult it is, I will prevail". This seems to carry a note of ambivalence, in that informants remind themselves that even though they have friends or family, they are alone and must take responsibility.

\section{Quantitative findings from the Norwegian sample}

Among the group of Norwegian youths, accomplishment together with well-being and relatedness stood out as the most important dimensions of sources of meaning, cf. 3.54 and 3.48 respectively (Table 3 ). Of the 26 sources of meaning, 11 were found to be significantly correlated with the experience of meaningfulness. Of these, strong correlations were found for generativity $\left(0.54^{* *}\right)$, explicit religiosity $\left(0.49^{* *}\right)$ and spirituality $\left(0.43^{* *}\right)$ among the young respondents. All dimensions of sources of meaning were significantly related to the experience of meaningfulness, except for liberality (Table 3). On the other hand, vertical self-transcendence, including organized religiousness and individual spirituality, had the lowest mean sum score (1.71), and thus turned out to be least important.

When comparing findings among the Norwegian youths in this sample with the Norwegian population in general ( $>22$ years old, $N=879$ ), the sum scores of the dimensions overall were at comparable levels (Table 3). The correlations of the dimensions related to meaningfulness, however, were stronger among the older respondents. Also, liberality was significantly related to meaningfulness, while this was not the case among the younger respondents. 


\begin{tabular}{|c|c|c|c|c|}
\hline & $\begin{array}{c}\text { Age } 17-22 \\
N=46 \\
M(S D)\end{array}$ & $\begin{array}{c}\text { Age }>22 \\
N=879 \\
M(S D)\end{array}$ & $\begin{array}{c}\text { Correlation with } \\
\text { Meaningfulness } \\
\text { (age 17-22, N = 46) }\end{array}$ & $\begin{array}{c}\text { Correlation with } \\
\text { Meaningfulness } \\
\text { (age }>22, N=879)\end{array}$ \\
\hline Well-being and relatedness & $3.48(0.63)$ & $3.40(0.60)$ & $0.36^{*}$ & $0.56^{* *}$ \\
\hline Community & & & $0.32^{*}$ & \\
\hline Care & & & $0.30^{*}$ & \\
\hline Attentiveness & & & $0.41^{* *}$ & \\
\hline Order and tradition & $3.19(0.52)$ & $3.35(0.59)$ & 0.16 & $0.34^{* *}$ \\
\hline Vertical self-transcendence & $1.71(1.23)$ & $1.90(1.24)$ & $0.52^{* *}$ & $0.59^{* *}$ \\
\hline Explicit rel & & & $0.49^{* *}$ & \\
\hline Spirituality & & & $0.43^{* *}$ & \\
\hline Horizontal self-transcendence & $2.91(0.72)$ & $3.15(0.64)$ & $0.43^{* *}$ & $0.53^{* *}$ \\
\hline Social commit & & & $0.39^{* *}$ & \\
\hline Nature & & & $0.31^{*}$ & \\
\hline Harmony & & & $0.31^{*}$ & \\
\hline Accomplishment & $3.54(0.52)$ & $3.10(0.62)$ & $0.30^{*}$ & $0.43^{* *}$ \\
\hline Generativity & & & $0.54^{* *}$ & \\
\hline Development & & & $0.32^{*}$ & \\
\hline Liberality & $3.23(0.63)$ & $2.95(0.66)$ & -0.06 & $0.20^{* *}$ \\
\hline
\end{tabular}

\section{Discussion}

The main findings were that the meaning aspects that could be identified in the interviews with young unaccompanied refugees were related to social relationships and loneliness, commitment to activities and goals beyond merely meeting their own needs and spirituality and religion. The study shows some differences between the two groups of young people in the data we analyzed. Among the young Norwegians, four sources of meaning were connected with meaningfulness. Of these four sources, they score the lowest on vertical and horizontal self-transcendence, which were the two sources that were emphasized most by the young refugees.

We are unable to know whether the issues that emerged are linked to characteristics of being a refugee such as separation, losses, resettlement and hardships, or to other factors, such as cultural issues, socioeconomic conditions, or maturing in adolescence and young adulthood in general, including independence and identity. What we do know from the interviews, however, is that they are lonely, and we have ascertained some of the problems they have. Even though this study did not include much information about the context in which the youths live and their backgrounds, we do know that socioeconomic challenges, language and culture difficulties, as well as previous loss and trauma mean that many would have to cope with difficult life situations. These factors are important in understanding the results. The young people taking part in study are from different ethnic groups and cultures. Many are from Afghanistan. In the research literature, Afghan culture is described as heterogeneous and multi-ethnic (Miszak and Monsutti, 2014), making it reasonable to assume that different Afghan youths experience and approach resettlement in a host country differently.

The qualitative findings were relatively similar to those found among Norwegian adolescents, although with some differences, and expressed differently. As the methods used with the two groups were different, it is only possible to compare the two groups to a limited degree. Although the aim is not to establish causality, the comparison with the Norwegian youths' meaning-making made our findings more salient.

Both the refugee youths and the Norwegians expressed that social relationships and connections to others were the most important factors for meaning. Moreover, both groups 
emphasized the importance of relatedness and generativity, i. e. commitment to worldly affairs beyond one's immediate needs. The main differences between the two groups were related to the significance attached to religion and to loneliness. Both loneliness and generativity are strongly linked to relatedness and could be seen as integral parts of interconnectedness and horizontal self-transcendence, but as these were important findings, they will also be discussed separately.

The findings of this study differ in some respects from other studies on unaccompanied minor refugees (Jensen et al., 2019; Carlson et al., 2012). Themes of trauma, mental health and resilience were not salient. This may be due to the way the interviews were conducted, and the fact that these were not topics in the interviews. However, it is still interesting that these themes, which otherwise are dominant in the literature, rarely emerged in the interviews, although there are many possible reasons for this Kohli (2006).

It is likely that hardships and atrocities the youths had experienced have impacted their expectations and moral development in some sense, but this was not a theme that emerged in the interviews. Many of the refugee children had witnessed human suffering and the consequences of violence and injustice. These types of experiences have been associated with moral injury, i.e. the long term impact such events and actions can have on people's expectations and moral beliefs (Litz et al., 2009), which again is associated with meaning and existential issues. Although the concept of moral injury is primarily applied to military populations (Currier et al., 2015) it may also be useful to understand other groups, including traumatized refugees (Mooren et al., 2019). One possibility is that these are not issues that the youths reflect on spontaneously. Another is that moral injury would only become a topic if one explicitly brings up potentially traumatizing experiences, as these may be associated with taboo or stigma, and as such not focusing on trauma could be seen as being part of the conspiracy of silence (McKinney, 2007). Alternatively, silence about certain topics could be a way to promote healing (Papadopoulos, 2018). However, the salience of loneliness and hopelessness that emerged, e.g. "No one can give me happiness although I am searching everywhere", could be interpreted as injured hope and expectation. Similarly, the focus on the mother may be an expression of a way of dealing with such moral injury. The earlier childhood experiences that young refugees had had are likely to have been important for their moral development (Bruning, 2018), although this was not a focus of the current study, including political and family violence. The general challenge of differentiating posttraumatic stress reactions from moral injuries (Bruning, 2018) is also likely to be an issue in this study, but neither were salient themes. However, one can interpret several of the statements as experiences of loss and grief, which are equally relevant. Grief and loneliness, however, may not have caused moral injury. This is exemplified by refugees' convictions regarding right and wrong, for example that it is right to help one's family, and that a mother would not hurt her child. Previous studies in the context of Afghanistan (Panter-Brick and Eggerman, 2012) on the fundamental role of cultural values for resilience, and the importance of honor and respectability are relevant.

\section{Spirituality and vertical self-transcendence}

For the unaccompanied refugees, religious expressions appear to be directly associated with an almighty God as a constant resource for meaning, support and comfort. Thus, vertical self-transcendence (Sørensen et al., 2019) in the form of organized religious practice and individual spirituality, was a salient theme. The informants seemed familiar with affiliation to an immaterial, supernatural reality concretized through what are called God and angels. Through individual prayer and an articulated relationship with God, the young refugees said they experienced comfort, help and meaning. Their references to God and prayer may be seen as part of the ontological significance of life. This is supported by a study of unaccompanied minors living in the Republic of Ireland (Ní Raghallaigh, 2011) where religious coping was found to be a relatively available and compelling way to deal 
with challenges. The authors found that religious faith and practice served as a source of continuity in their lives, and that facing an unfamiliar context, belief in God could represent something familiar. In addition, the young people's relationships with God gave them a sense of meaning and comfort and of increased control.

In contrast, in the Norwegian sample, religion and spirituality was not a salient theme. The reasons why this was not an important theme among the Norwegians may be numerous. For example, it might be because of the relatively subdued role that religion plays in Norwegian culture, or that religion is primarily regarded as a private matter. Despite vertical selftranscendence, including religion and spirituality having low scores in the Norwegian youth sample, the SD level may indicate that this feature is quite important for some of the youth. This is supported by the strong correlation between vertical self-transcendence and meaningfulness $\left(0.52^{* *}\right)$. Moreover, it is possible that the quantitative questionnaires were less likely to capture spirituality in this population.

\section{Relatedness, tradition and well-being}

With regard to sources of meaning (Sørensen et al., 2019), relatedness was present among the refugee youths, especially expressed through a commitment toward caring for family members and at the same time caring for themselves. Further, there was a link between this factor and generativity, with the latter expressed by schoolwork and earning money as a basis for unselfish support of their families' welfare across generations. Thus, social relations (relatedness) and generativity were linked, and this became particularly clear in the qualitative data. For example, sending money to the mother may be a way to show that the refugee is doing well, perhaps to reassure his family that they need not worry, to preserve his dignity, or to continue to be part of the family. The duty to help others, in particular the family, may also be seen as "order", i.e. a person's relation to tradition and morality.

A distinct feature of the narratives of the young refugees was the strong connection to their mothers. The high value assigned to the mother was affiliated with social commitment, order and interconnectedness. To fulfill the wishes of the mother may be interpreted as fulfilling the needs of the family, as well as part of family tradition and order. However, in interpreting the expressed value of family, one should keep in mind that memories of violent events are malleable and depend on social experiences (Panter-Brick et al., 2015). The mother emerged as more than a parent and seemed to be a main source of meaning. Being able to fulfil mother's wishes seemed to provide purpose in life, thus, being a main source through horizontal self-transcendence. However, literature searches reveal a sparsity of empirical knowledge on this issue. The strong influence and near worship of the mother might be a cultural phenomenon, possibly suggesting that women are the family heads in some respect, and the persons to whom to turn for emotional and practical support. Women may have been part of military and terrorist groups to a lesser extent than men (Dearing, 2010), and the rare mention of fathers in the refugee boys' narratives may be related to fathers' absence due to combat or death.

The current findings can be seen in light of Afghan cultural values, as they help make sense of suffering and provide an order to life, and importantly, point to family relationships and family unity (Panter-Brick and Eggerman, 2012).

Thus, social relationships and interconnectedness were central themes in the interviews and were related to religion (vertical self-transcendence), family, especially the mother (horizontal self-transcendence), order and accomplishments. This is supported by many psychological theories and studies on well-being, where social connectedness is central (Deci and Ryan, 2000; Delle Fave and Soosai-Nathan, 2014; Forgeard et al., 2011). For example, friendship, love and the ability to connect with others are common themes in the classic works by Allport, Maslow and Erikson, and the role of perceived and received social 
support is widely studied, especially as a predictor of health and well-being (Harandi et al., 2017). The findings in this study also are also interpreted as showing close relationship between meaning and social relationships, i.e. interconnectedness, in line with relevant frameworks (Delle Fave and Soosai-Nathan, 2014). Other studies on refugees have also emphasized the importance of relations and social networks. For example, one study on Syrian refugees' social capital in Germany found context and meaning-making within supportive ties to be important in two types of relations which help in the transition from refugee to established residents, from asymmetric, which maintains refugee positioning, to egalitarian, which overcomes refugee-related positionings (Bernhard, 2020).

\section{Accomplishment, generativity}

In the qualitative material we saw that relation to the immediate family and the wish to provide for their well-being was important for the young refugees. Goal directedness or purposefulness (Frankl, 1985) were also salient themes and were also related to supporting their family and becoming financially independent. According to the quantitative findings in the Norwegian youth sample (Pedersen et al., 2018) the dimension "Well-being and relatedness", and especially its sub-scales "community", "care" and "attentiveness". In addition, a strong correlation between meaningfulness and generativity was observed. Generativity refers to unselfish activities toward the best for others beyond one's own immediate needs and is found to be a source of meaning that correlates strongly with meaningfulness in several studies (Pedersen et al., 2018; Schnell, 2009; Sørensen et al., 2019). Together with relatedness, generativity may be especially important for the young refugees in their special situation. Even though their family is far away, they still want to contribute and provide for them as well as to commit themselves to make a difference in relation to others in general. As such, both relatedness and generativity may also be part of distal and symbolic interconnectedness (Delle Fave and Soosai-Nathan, 2014), as well as aspirations in general (Vervliet et al., 2015).

Few studies have investigated the role of relatedness and generativity among adolescents. One study of coping strategies among unaccompanied refugee youths from Sudan who grew up amid violence and loss found that the most frequently used coping strategies were collectivity and the communal self, suppression and distraction, making meaning, and emerging from hopelessness to hope (Goodman, 2004).

In the Norwegian youth sample, we saw that neither the dimension of liberality, nor the subdimensions freedom or individualism were associated with the experience of meaningfulness. It is difficult to determine the importance of these factors for the young refugees, although individuals seem to acknowledge the value of "making it on my own" which may refer to liberality or accomplishment.

\section{Loneliness}

Loneliness was the third main issue and the one where findings among the refugee youths differed from the findings in the Norwegian sample. To be alone was both a freedom and a possibility to actualize oneself, but it appeared to be linked with a strong feeling of being alone with limited connectedness to their former world, especially family and the mother. An important aspect in refugee youths' loneliness is relationships with their peers and whom they could trust in the future (Eide et al., 2020). The many and changing relationships, not least with professional helpers, that characterized their social context in Norway (Eide et al., 2020) may also have contributed toward the sense of loneliness. Considering findings from a study in Germany (Bernhard, 2020), we may speculate that the youths were in a relatively early phase of resettlement, and it is likely that they had not yet established relations that were egalitarian and helping to phase out the refugee position, which may also be part of loneliness (Bernhard, 2020). 
A study of unaccompanied young refugees living in a rural village in Sweden (Wernesjö, 2015), provides a deeper understanding of what constitutes a sense of home and belonging. They found that belonging and home were understood as ongoing processes that are negotiated with others, and via processes of othering and rationalization. These may be important as coping strategies to avoid loneliness. In a study of unaccompanied minors living in Ireland, some of the coping strategies were maintaining continuity in a changed context, adjusting by learning and changing, suppressing emotions and seeking distraction, and acting independently (Ní Raghallaigh, 2011). These patterns seem to mirror the findings in the current study.

\section{Strengths and limitations}

The secondary design inevitably means we lacked control over what questions were asked and how they were followed up. For example, well-being and meaning were not the focus of the interviews. However, the fact that the principal author of the original study also took part in the current study, increases the likelihood that the data were used appropriately and resulted in a more robust analysis. Furthermore, we consider that the research questions in the original study and the current study were close enough in intent and topic for the primary data to be valid in the current study as well (Hinds et al., 1997).

The quantitative data were not collected to provide a comparison group, and the methods used were very different. Hence, the analyses of similarities and differences are limited, although the quantitative data were reanalyzed for the current study. However, explanations and comparisons were not the primary objective of the study, but were instead intended to explore the spontaneous references to meaning. It is interesting that common concepts and patterns could be identified among the Norwegian and the refugee groups.

We have not been able to find other studies with a similar approach and method, which obviously makes it difficult to make direct comparisons with other studies. As such, this study adds to reflections of the significance of development and youth and avoids the problem of interpreting all findings in the light of being a refugee, and instead points to the fundamental importance of being human and being a young developing person, not solely being a refugee. The similarities and differences in the groups that could be explored further include religion and connectivity.

The secondary analysis design of this study allowed us to explore the expressions and experience of meaning among young refugees who were separated from their families without meaning being the focus of discussion. This helps to avoid the underuse of a data set (Hinds et al., 1997). Furthermore, it avoided putting additional pressure on a group of potentially vulnerable people to explore topics that may be painful, or putting them in a situation where they would be asked to discuss topics or use terms they may not be comfortable or familiar with.

It can be seen as a strength of this study that existential issues still emerged as salient issues despite this topic not being a focus of the interviews, as it means these narratives were not the interviewers' anticipated results. If trauma and hardships had been issues that were addressed specifically in the interviews, as in many other studies among refugees (Matos et al., 2018; Mooren et al., 2019; Tekie, 2018), it would perhaps have been natural that meaning would also have been included as a topic, but this was not the case. However, as the word "meaning" was not used in the original study, we have advanced a number of interpretations, and relied heavily on the theory of meaning-making. Similarly, although the participants in the current study did not use words like "meaning in life", their narratives addressed meaning components like sense of coherence in life by making links between Norway and their country of origin, between past and present, and importantly, between life alone and life with their family, especially the mother. 


\section{Implications and conclusion}

This study takes an unusual starting point, namely, young refugees' sources of meaning in the first settlement phase, which is a period thoroughly documented by previous research as difficult. We found that mother and God (vertical and horizontal self-transcendence) are the most important sources of meaning, and that this is different from the young people in the non-refugee population and may be attributed to being in a difficult life situation. This comparison indicates that research should focus not only on risk and protective factors of being a refugee, but also on developmental factors. Meaning-making is part of growing up and becoming an adult and is important for health and well-being.

The results suggest that meaning and meaning-making among young unaccompanied refugees settled in Norway are important, and as for Norwegian youth, health and wellbeing is centered around social relationships. Moreover, this study suggests that loneliness and the importance of connections to other people, including family members who live far away, as well as religion, should be considered in efforts to provide effective support to young refugees who live alone. The findings on the importance of relatedness and generativity for young refugees, suggest that the host country should consider ways to facilitate activities that promote social relations and the experiences of helping others and making a difference. A better understanding of refugee youths' meaning-making and how it is the same as and different from that of other young people may be useful knowledge for those who work with young unaccompanied minors in the arrival and settlement phases. The study is a reminder that young refugees are the same as other young people, but have some additional needs that may be different.

\section{References}

Alemi, Q., Stempel, C., Koga, P.M., Montgomery, S., Smith, V., Sandhu, G., Villegas, B. and Requejo, J. (2018), "Risk and protective factors associated with the mental health of young adults in Kabul", Afghanistan. BMC Psychiatry, Vol. 18, pp. 1-10.

Beal, S.J., Crockett, L.J. and Peugh, J. (2016), "Adolescents' changing future expectations predict the timing of adult role transitions", Developmental Psychology, Vol. 52 No. 10, p. 1606.

Bernhard, S. (2020), "Reaching in: meaning-making, receiving context and inequalities in refugees' support networks", The Sociological Review, p. 0038026120945608.

Bonanno, G.A. and Mancini, A.D. (2008), "The human capacity to thrive in the face of potential trauma", PEDIATRICS, Vol. 121 No. 2, pp. 369-375.

Braun, V. and Clarke, V. (2006), "Using thematic analysis in psychology", Qualitative Research in Psychology, Vol. 3 No. 2, pp. 77-101.

Bruning, M.D. (2018), "Children, war, and moral injury", Military Behavioral Health, Vol. 6 No. 2, pp. 143-150.

Carlson, B.E., Cacciatore, J. and Klimek, B. (2012), "A risk and resilience perspective on unaccompanied refugee minors", Social Work, Vol. 57 No. 3, pp. 259-269.

Crosnoe, R. and Johnson, M.K. (2011), "Research on adolescence in the twenty-first century", Annual Review of Sociology, Vol. 37 No. 1, pp. 439-460.

Currier, J.M., Holland, J.M. and Malott, J. (2015), "Moral injury, meaning making, and mental health in returning veterans", Journal of Clinical Psychology, Vol. 71 No. 3, pp. 229-240.

Dearing, M.P. (2010), "Like red tulips at springtime: understanding the absence of female martyrs in Afghanistan", Studies in Conflict \& Terrorism, Vol. 33 No. 12, pp. 1079-1103.

Deci, E.L. and Ryan, R.M. (2000), "The, what and why of goal pursuits: human needs and the selfdetermination of behavior", Psychological Inquiry, Vol. 11 No. 4, pp. 227-268.

Delle Fave, A. and Soosai-Nathan, L. (2014), "Meaning as inter-connectedness: theoretical perspectives and empirical evidence", Journal of Psychology in Africa, Vol. 24 No. 1, pp. 33-43. 
Ehntholt, K.A., Trickey, D., Harris Hendriks, J., Chambers, H., Scott, M. and Yule, W. (2018), "Mental health of unaccompanied asylum-seeking adolescents previously held in British detention centres", Clinical Child Psychology and Psychiatry, Vol. 23 No. 2, pp. 238-257.

Eide, K., Lidén, H., Haugland, B., Fladstad, T. and Hauge, H.A. (2020), "Trajectories of ambivalence and trust: experiences of unaccompanied refugee minors resettling in Norway", European Journal of Social Work, Vol. 23 No. 4, pp. 554-565.

Fazel, M. (2018), "Psychological and psychosocial interventions for refugee children resettled in highincome countries", Epidemiology and Psychiatric Sciences, Vol. 27 No. 2, pp. 117-123.

Fazel, M., Reed, R.V., Panter-Brick, C. and Stein, A. (2012), "Mental health of displaced and refugee children resettled in high-income countries: risk and protective factors", The Lancet, Vol. 379 No. 9812 , pp. 266-282.

Fladstad, T. (2014), "A brick in the wall: reflections on relational ethics", Nordic Work with Traumatised Refugees: Do we Really Care, pp. 144-153.

Forgeard, M.J., Jayawickreme, E., Kern, M.L. and Seligman, M.E. (2011), "Doing the right thing: measuring wellbeing for public policy”, International Journal of Wellbeing, Vol. 1.

Frankl, V.E. (1985), Man’s Search for Meaning, Simon and Schuster.

Goodman, J.H. (2004), "Coping with trauma and hardship among unaccompanied refugee youths from Sudan", Qualitative Health Research, Vol. 14 No. 9, pp. 1177-1196.

Harandi, T.F., Taghinasab, M.M. and Nayeri, T.D. (2017), "The correlation of social support with mental health: a Meta-analysis”, Electronic Physician, Vol. 9 No. 9, pp. 5212.

Hayes, S.W. and Endale, E. (2018), "Sometimes my mind, it has to analyze two things': identity development and adaptation for refugee and newcomer adolescents", Peace and Conflict: Journal of Peace Psychology, Vol. 24 No. 3, p. 283.

Hebebrand, J., Anagnostopoulos, D., Eliez, S., Linse, H., Pejovic-Milovancevic, M. and Klasen, H. (2016), A First Assessment of the Needs of Young Refugees Arriving in Europe: what Mental Health Professionals Need to Know, Springer.

Herz, M. and Lalander, P. (2017), "Being alone or becoming lonely? The complexity of portraying "unaccompanied children'as being alone in Sweden", Journal of Youth Studies, Vol. 20 No. 8, pp. 1062-1076.

Hinds, P.S., Vogel, R.J. and Clarke-Steffen, L. (1997), "The possibilities and pitfalls of doing a secondary analysis of a qualitative data set”, Qualitative Health Research, Vol. 7 No. 3, pp. 408-424

Hopkins, P. (2008), "Ethical issues in research with unaccompanied asylum-seeking children", Children's Geographies, Vol. 6 No. 1, pp. 37-48.

Jensen, T.K., Fjermestad, K.W., Granly, L. and Wilhelmsen, N.H. (2015), "Stressful life experiences and mental health problems among unaccompanied asylum-seeking children", Clinical Child Psychology and Psychiatry, Vol. 20 No. 1, pp. 106-116.

Jensen, T.K., Skar, A.-M.S., Andersson, E.S. and Birkeland, M.S. (2019), "Long-term mental health in unaccompanied refugee minors: pre-and post-flight predictors", European Child \& Adolescent Psychiatry, Vol. 28 No. 12, pp. 1671-1682.

Kohli, R.K. (2006), "The sound of silence: listening to what unaccompanied asylum-seeking children say and do not say", British Journal of Social Work, Vol. 36 No. 5, pp. 707-721.

Litz, B.T., Stein, N., Delaney, E., Lebowitz, L., Nash, W.P., Silva, C. and Maguen, S. (2009), "Moral injury and moral repair in war veterans: a preliminary model and intervention strategy", Clinical Psychology Review, Vol. 29 No. 8, pp. 695-706.

Malterud, K., Siersma, V.D. and Guassora, A.D. (2016), "Sample size in qualitative interview studies: guided by information power", Qualitative Health Research, Vol. 26 No. 13, pp. 1753-1760.

Matos, L., Indart, M., Park, C. and Leal, I.P. (2018), "Meaning-making and psychological adjustment following refugee trauma", Actas Do, Vol. 12, pp. 513-521.

Mckinney, K. (2007), "Breaking the conspiracy of silence': testimony, traumatic memory, and psychotherapy with survivors of political violence", Ethos, Vol. 35 No. 3, pp. 265-299.

Miszak, N. and Monsutti, A. (2014), "Landscapes of power: local struggles and national stakes at the rural-urban fringe of Kabul", The Journal of Peasant Studies, Vol. 41 No. 2, pp. 183-198. 
Mooren, N., DE LA Rie, S. and Boelen, P. (2019), "Moral injury in refugees with PTSD: an explorative study", European Journal of Psychotraumatology, Vol. 10, pp. 75-76.

Moshuus, G.H. and Eide, K. (2016), "The indirect approach: how to discover context when studying marginal youth”, International Journal of Qualitative Methods, Vol. 15 No. 1, p. 1609406916656193.

Ní Raghallaigh, M. (2011), "Religion in the lives of unaccompanied minors: an available and compelling coping resource", British Journal of Social Work, Vol. 41, pp. 539-556.

Oppedal, B., Ramberg, V. and Røysamb, E. (2020), "The asylum-process, bicultural identity and depression among unaccompanied young refugees", Journal of Adolescence, Vol. 85, pp. 59-69.

Panter-Brick, C. and Eggerman, M. (2012), "Understanding culture, resilience, and mental health: the production of hope", The Social Ecology of Resilience, Springer.

Panter-Brick, C., Eggerman, M., Mojadidi, A. and Mcdade, T.W. (2008), "Social stressors, mental health, and physiological stress in an urban elite of young Afghans in Kabul", American Journal of Human Biology, Vol. 20 No. 6, pp. 627-641.

Panter-Brick, C., Grimon, M.P., Kalin, M. and Eggerman, M. (2015), "Trauma memories, mental health, and resilience: a prospective study of Afghan youth", Journal of Child Psychology and Psychiatry, Vol. 56 No. 7, pp. 814-825.

Papadopoulos, R.K. (2018), Therapeutic Care for Refugees: No Place like Home, Routledge.

Pedersen, H.F., Birkeland, M.H., Jensen, J.S., Schnell, T., Hvidt, N.C., Sørensen, T. and LA Cour, P. (2018), "What brings meaning to life in a highly secular society? A study on sources of meaning among danes", Scandinavian Journal of Psychology, Vol. 59 No. 6, pp. 678-690.

Ritchie, J., Lewis, J., Nicholls, C.M. and Ormston, R. (2013), Qualitative Research Practice: A Guide for Social Science Students and Researchers, Sage.

Røysamb, E. and Nes, R.B. (2016), "Genes, environments and core features of eudaimonic wellbeing", Handbook of Eudaimonic Well-Being, Springer.

Schnell, T. (2009), "The sources of meaning and meaning in life questionnaire (SoMe): relations to demographics and well-being", The Journal of Positive Psychology, Vol. 4 No. 6, pp. 483-499.

Schnell, T. (2011), "Individual differences in meaning-making: considering the variety of sources of meaning, their density and diversity", Personality and Individual Differences, Vol. 51 No. 5, pp. 667-673.

Sierau, S., Schneider, E., Nesterko, Y. and Glaesmer, H. (2019), "Alone, but protected? Effects of social support on mental health of unaccompanied refugee minors", European Child \& Adolescent Psychiatry, Vol. 28 No. 6, pp. 769-780.

Silove, D. (2013), "The ADAPT model: a conceptual framework for mental health and psychosocial programming in post conflict settings", Intervention, Vol. 11 No. 3, pp. 237-248.

Sørensen, T., LA Cour, P., Danbolt, L.J., Stifoss-Hanssen, H., Lien, L., Demarinis, V., Pedersen, H.F. and Schnell, T. (2019), "The sources of meaning and meaning in life questionnaire in the norwegian context: relations to mental health, quality of life, and self-efficacy", The International Journal for the Psychology of Religion, Vol. 29 No. 1, pp. 32-45

Steger, M.F. (2012), "Making meaning in life", Psychological Inquiry, Vol. 23 No. 4, pp. 381-385.

Stewart, D.W., Stewart, D.W. and Kamins, M.A. (1993), Secondary Research: Information Sources and Methods, Sage.

Tekie, Y.T. (2018), "The role of Meaning-Making in posttraumatic growth among eritrean refugees with posttraumatic stress disorder", PhD, University of Tennessee.

Tong, A., Sainsbury, P. and Craig, J. (2007), "Consolidated criteria for reporting qualitative research (COREQ): a 32-item checklist for interviews and focus groups", International Journal for Quality in Health Care, Vol. 19 No. 6, pp. 349-357.

Vervliet, M., Lammertyn, J., Broekaert, E. and Derluyn, I. (2014), "Longitudinal follow-up of the mental health of unaccompanied refugee minors", European Child \& Adolescent Psychiatry, Vol. 23 No. 5, pp. 337-346.

Vervliet, M., Vanobbergen, B., Broekaert, E. and Derluyn, I. (2015), "The aspirations of Afghan unaccompanied refugee minors before departure and on arrival in the host country", Childhood, Vol. 22 No. 3, pp. 330-345. 
Wernesjö, U. (2015), "Landing in a rural village: home and belonging from the perspectives of unaccompanied young refugees", Identities, Vol. 22 No. 4, pp. 451-467.

\section{Author affiliations}

Ragnhild Dybdahl is based at the Department of Social Work, Child Welfare and Social Policy, Oslo Metropolitan University, Oslo, Norway and Centre for Crisis Psychology, University of Bergen, Bergen, Norway.

Torgeir Sørensen is based at the Centre for Diaconia and Professional Practice, VID Specialized University, Oslo, Norway.

Hans A. Hauge is based at the Department of Health, Social and Welfare Studies, University of South-Eastern Norway Campus Porsgrunn, Porsgrunn, Norway.

Kjersti Røsvik is based at the Department of Health, Social and Welfare Studies, University of South-Eastern Norway Campus Porsgrunn, Porsgrunn, Norway.

Lars Lien is based at the Faculty of Health and Social Sciences, Inland Norway University of Applied Sciences Hamar Campus, Hamar, Norway.

Ketil Eide is based at the Department of Health, Social and Welfare Studies, University of South-Eastern Norway Campus Porsgrunn, Porsgrunn, Norway.

\section{Corresponding author}

Ragnhild Dybdahl can be contacted at: ragndy@oslomet.no

For instructions on how to order reprints of this article, please visit our website: www.emeraldgrouppublishing.com/licensing/reprints.htm

Or contact us for further details: permissions@emeraldinsight.com 